Article

\title{
Direct Fixed-Step Maximum Power Point Tracking Algorithms with Adaptive Perturbation Frequency
}

\author{
Eyal Amer ${ }^{1}$, Alon Kuperman ${ }^{1, *(1)}$ and Teuvo Suntio ${ }^{2}$ (I) \\ 1 Applied Energy Laboratory, Department of Electrical and Computer Engineering, Ben-Gurion University of \\ the Negev, Beer-Sheva 8410501, Israel; eyalamer@gmail.com \\ 2 Laboratory of Electrical Energy Engineering, Tampere University of Technology, Tampere 33720, Finland; \\ teuvo.suntio@tut.fi \\ * Correspondence: alonk@bgu.ac.il; Tel.: +972-8-6461-599
}

Received: 20 December 2018; Accepted: 24 January 2019; Published: 27 January 2019

\begin{abstract}
Owing to the good trade-off between implementation and performance, fixed-step direct maximum power point tracking techniques (e.g., perturb and observe and incremental conductance algorithms) have gained popularity over the years. In order to optimize their performance, perturbation frequency and perturbation step size are usually determined a priori. While the first mentioned design parameter is typically dictated by the worst-case settling time of the combined energy conversion system, the latter must be high enough to both differentiate the system response from that caused by irradiation variation and match the finite resolution of the analog-to-digital converter in case of digital implementation. Well-established design guidelines, however, aim to optimize steady-state algorithm performance while leaving transients nearly untreated. To improve transient behavior while keeping the steady-state operation unaltered, variable step direct maximum power point tracking algorithms based on adaptive perturbation step size were proposed. This paper proposes a concept of utilizing adaptive perturbation frequency rather than variable step size, based on recently revised guidelines for designing fixed-step direct maximum power point tracking techniques. Preliminary results demonstrate the superiority of the proposed method over adaptive perturbation step size operation during transients, without compromising the steady state performance.
\end{abstract}

Keywords: photovoltaic generators; maximum power point tracking; step size; perturbation frequency

\section{Introduction}

Energy produced by a photovoltaic generator (PVG) is mainly dependent on a single (referred to as the "energy generating") parameter: Solar irradiation. In addition, PVG power is load dependent and affected by temperature. As a result, the PVG power curve is characterized by a single maximum power point (MPP) on a single unit level for a specific set of environmental variables. Consequently, generalized electrical characteristics of a PVG are represented by a family of power curves for a range of solar irradiations and temperatures [1]. Upon variation of one or both environmental variables, locations of MPP current and voltage-and hence power-change. Such a behavior calls for instantaneous maximum power point tracking (MPPT) in order to optimize PVG economical utilization [2].

Comparison of different MPPT algorithms presented in the literature so far may be found [3-11]. Owing to their inherently generic nature and relatively simple implementation, direct non-model-based techniques, such as perturb and observe (PO) [12,13], incremental conductance [14,15] and extremum seeking or ripple correlation control [16-20], are probably the most widely applied MPPT methods. While well-established, fixed step versions of MPPT algorithms suffer from the well-known trade-off 
between transient and steady-state operation [21]. In order to tackle this drawback, adjustable (or adaptive) step size versions of non-model-based algorithms have been proposed [22-38], in which the step size is adjusted, typically in proportion to the derivative of PVG power with respect to control variable. Indeed, such algorithms demonstrate superiority over the fixed step versions, achieved at the expense of more complex implementation. It is interesting to note that the performance similarity of fixed step direct non-model-based algorithms versions have been revealed $[39,40]$, while the equivalence of major variable step size MPPT algorithms has been demonstrated [41].

Consider, without loss of generality, a photovoltaic energy conversion operating under a single-loop direct non-model based MPPT. For example, the interfacing power converter (IPC) duty cycle is the perturbed variable (see Figure 1a). A small perturbation $\Delta d$ is injected into the system every $T_{p}$ seconds. Following a $T_{\Delta}$-lasting transient, the corresponding change in generated power is observed either at the PVG or load side (see Figure 1b), and the next perturbation polarity (in fixed step versions) and size (in variable step versions) is determined so that the operation point is driven towards the MPP. It was shown in References $[13,21]$ that the maximum perturbation frequency (reciprocal of $T_{p}$ ) is limited by settling time of the generated power transient induced by the perturbation while the minimum perturbation step size depends on the maximum expected irradiation variation rate and sensing resolution. Recently, the authors of References [42,43] have refined the above design guidelines, proving that the maximum perturbation frequency should be designed at the short-circuit operating point while the minimum perturbation step size should be designed at the maximum power point, both corresponding to standard test conditions.

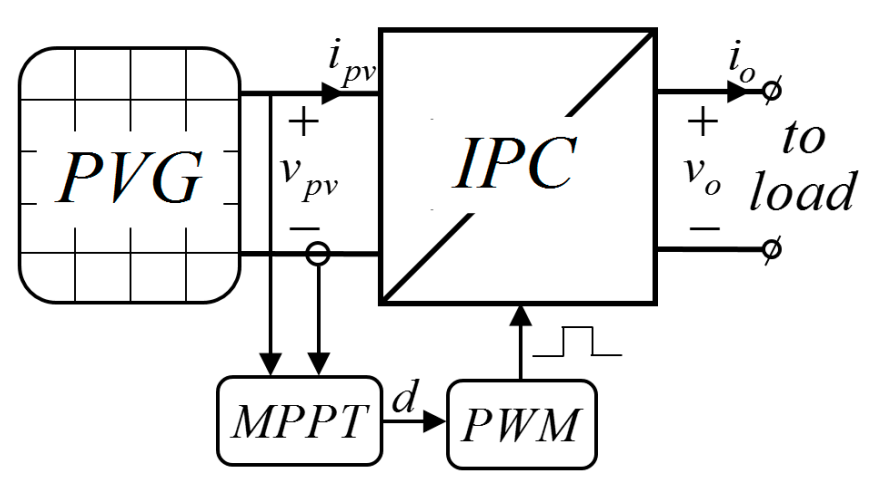

(a) typical combined PVG-IPC system

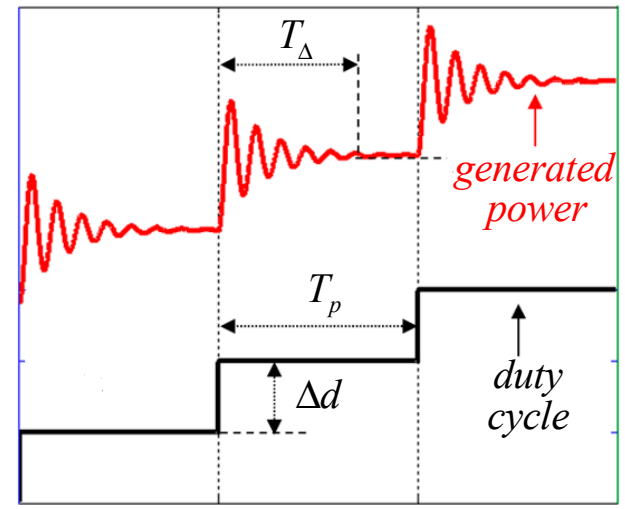

(b) short-time system dynamics

Figure 1. Photovoltaic energy conversion under direct non-model based maximum power point tracking (MPPT) technique

Once the design guidelines briefly reviewed above are respected, stable three-point behavior is ensured in steady-state [21]. It is therefore commonly assumed that if the selected $T_{p}$ is too small, the MPPT algorithm can be confused and the operating point may become unstable, bringing disordered or chaotic behaviors into the system. On the other hand, selecting a $T_{p}$ that is too long penalizes MPPT convergence speed and efficiency. Therefore, in order to improve the performance of the fixed-step based MPPT algorithm, variable step size methods should utilize adaptive step size while keeping the perturbation frequency constant. Increasing the perturbation step size when the operation point is far from the MPP and decreasing it in the MPP vicinity is, therefore, the main concept of such algorithms. Unfortunately, step size increase yields correspond to an increase of transients. In addition, because MPP voltage is nearly independent of irradiation, variable step MPPT algorithms tend to be confused upon irradiation changes [21]. On the other hand, applications of direct non-model based MPPT algorithms with a perturbation period much lower than the settling time of the system response were reported in References [44,45]. It was shown that faster responses to irradiance changes were achieved, yet steady-state oscillations were larger than those for the perturbation frequency 
dictated by design guidelines. Nevertheless, experimental investigation alone was conducted without a solid analytical background. The only attempt made to vary the perturbation frequency followed by a theoretical framework was made in Reference [46]. However, the effect of the PVG on the system dynamics was completely disregarded and, therefore, the presented outcomes are not consistent with the design guidelines above. The effect of PVG on generated power dynamics is extremely significant $[47,48]$ and must be considered during MPPT algorithm design, since the boundary value of the perturbation frequency is dependent on PVG parameters.

Inspired by the promising results demonstrated in References [44,45], this paper proposes to combine the advantages of operating with high perturbation frequency values during transients and the design-guideline-imposed values of the perturbation frequency in steady state, while maintaining the step size at minimum value, as dictated by the fixed-step algorithm design guidelines. Such a concept yields a fixed-step variable-perturbation-frequency MPPT algorithm. The proposed technique has the ability of accelerating the transients caused by either system initialization away from MPP or sudden irradiation changes while maintaining accuracy during a steady-state regime. Preliminary results demonstrate the superiority of the proposed approach over fixed-step and fixed-frequency methods, as well as over variable-step approaches.

The rest of the paper is organized as follows: A review of PVG properties is briefly given in Section 2. Combined PVG-IPC-load dynamics are derived in Section 3. The principle of adaptive step MPPT algorithms is given in Section 4, followed by the proposed concept of adaptive perturbation frequency algorithms in Section 5. An example comparing the performance of different approaches is discussed in Section 6. The conclusions are drawn in Section 7.

\section{The Photovoltaic Generator}

A generalized PVG equivalent circuit is shown in Figure 2a [49]. It consists of a photo current source $i_{P}$; a current source $i_{D}$, representing the current of $k$ parallel-connected semiconductor diodes, is given by

$$
i_{D}=\sum_{k} I_{0 k}\left(\exp \left\{\frac{v_{P V}-r_{S} i_{P V}}{\alpha_{k} V_{T}}\right\}-1\right)
$$

where $I_{0 k}$ and $\alpha_{k}$ symbolize the reverse saturation current and ideality factor of the $k$-th diode, and $V_{T}$ denotes thermal voltage; equivalent capacitance is $c_{P V}$, and the equivalent shunt and series resistances are $r_{S H}$ and $r_{S}$, respectively. The equivalent capacitance $c_{P V}$ is small and its value may be neglected since it is typically offset by the value of IPC input capacitance. Equivalent circuit components are environmental variables dependent as follows: the photocurrent $i_{P}$ depends on both irradiation and temperature; the diode current $i_{D}$ is temperature dependent and irradiation independent. The resistances are typically considered independent environmental variables, even though $r_{S H}$ possesses some irradiation dependence.

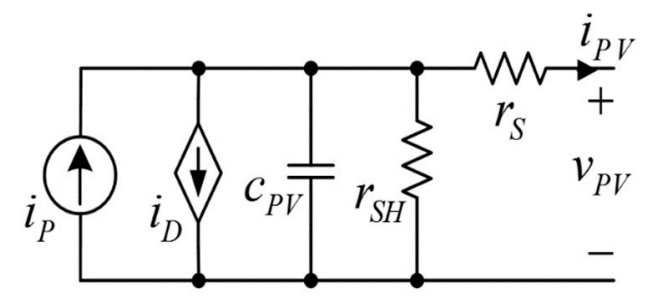

(a) Detailed.

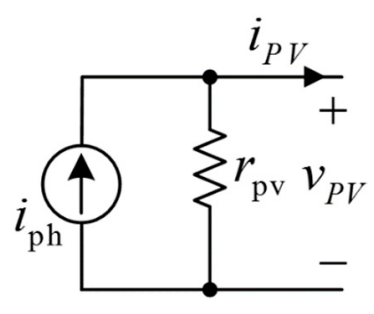

(b) Norton.

Figure 2. Photovoltaic generator (PVG) equivalent circuit.

All the equivalent circuit parameters may be estimated either from experimental measurements or extracted from the manufacturer's datasheets [50,51]. Consequently, the detailed PVG equivalent 
circuit may be rearranged into a simplified dynamic Norton representation, as shown in Figure $2 \mathrm{~b}$. Norton and detailed equivalent circuit parameters are related as

$$
r_{p v}=r_{S}+r_{S H}|| r_{D}, \quad i_{p h}=i_{P} \frac{r_{S H} \| r_{D}}{r_{p v}}
$$

with

$$
r_{D}=\frac{\partial v_{p v}}{\partial i_{D}}
$$

representing the equivalent dynamic resistance of $i_{D}$. It may be concluded that the value of PVG dynamic resistance $r_{p v}$ depends on both environmental variables and is also influenced by the operating point. In cases where a typical single-diode equivalent circuit is considered (i.e., for $k=1$ in Equation (1)), PVG dynamic resistance may be reformulated into

$$
r_{p v}=r_{S}+\frac{r_{S H}}{1+W\left(\frac{I_{0} r_{S H}}{\alpha V_{T}} \exp \left(\frac{r_{S H}\left(i_{P}-I_{0}-i_{P V}\right)}{\alpha V_{T}}\right)\right)},
$$

where $W(\cdot)$ stands for the Lambert-W function. According to the analysis in Reference [31], the practical PVG dynamic resistance at short circuit (SC) and open circuit (OC) conditions may be approximated as

$$
\left.r_{p v}\right|_{S C} \approx r_{S H}
$$

and

$$
\left.r_{p v}\right|_{O C} \approx r_{S},
$$

respectively, since $W(x)<<1$ for $x<<1, W(x)>>1$ for $x>1$ and $r_{S H}>>r_{S}$. It is then concluded that in PVG, dynamic resistance generally resides within the $\left[r_{S}, r_{S H}\right]$ region of values throughout the whole operation range. Therefore, for any MPP, the following holds;

$$
\left.r_{p v}\right|_{O C}<\left.r_{p v}\right|_{M P P}<\left.r_{p v}\right|_{S C}
$$

\section{Photovoltaic Generator (PVG) Power Dynamics in a Combined PVG-IPC-Load System}

Referring to the systems in Figures $1 \mathrm{a}$ and $2 \mathrm{~b}$ while defining PVG dynamic conductance as $Y_{p v}=$ $1 / r_{p v}$, combined small-signal system dynamics are given by $[52,53]$

$$
\begin{aligned}
& \hat{v}_{p v}=\frac{Z_{i n}}{1+Z_{i n} Y_{p v}} \hat{i}_{p h}+\frac{T_{o i}}{1+Z_{i n} Y_{p v}} \hat{v}_{\mathrm{O}}+\frac{G_{c i}}{1+Z_{i n} Y_{p v}} \hat{d} \\
& \hat{i}_{p v}=\frac{1}{1+Z_{i n} Y_{p v}} \hat{i}_{p h}-\frac{Y_{p v} T_{o i}}{1+Z_{i n} Y_{p v}} \hat{v}_{\mathrm{O}}-\frac{Y_{p v} G_{c i}}{1+Z_{i n} Y_{p v}} \hat{d},
\end{aligned}
$$

where $\hat{d}$ denotes the IPC duty cycle; $G_{c i}, T_{o i}$, and $Z_{\text {in }}$ symbolize the IPC control-to-input-voltage transfer function, output-to-input voltage transfer function, and input impedance, respectively. The temperature effect is disregarded in Equation (8) due to its relatively slow dynamics. The resulting small signal PVG power dynamics are given by [42]

$$
\hat{p}_{p v}=I_{p v} \hat{v}_{p v}+V_{p v} \hat{i}_{p v}+\hat{i}_{p v} \hat{v}_{p v}
$$

with $\left(I_{p v}, V_{p v}\right)$ representing the PVG operating point, further rearranged as

$$
\hat{p}_{p v} \approx V_{p v}\left(\frac{1}{R_{p v}}-\frac{1}{r_{p v}}\right) \hat{v}_{p v}-\frac{1}{r_{p v}} \hat{v}_{p v}^{2}
$$

with

$$
R_{p v}=\frac{V_{p v}}{I_{p v}}
$$


representing PVG static resistance. Taking into account the following static and dynamic resistances relation

$$
\begin{aligned}
& r_{p v}>>R_{p v}, \quad v_{p v}<<\left.v_{p v}\right|_{M P P} \\
& r_{p v} \approx R_{p v},\left.\quad v_{p v} \approx v_{p v}\right|_{M P P} \\
& r_{p v}<<R_{p v}, \quad v_{p v}>>\left.v_{p v}\right|_{M P P}
\end{aligned}
$$

The small-signal dynamics of PVG power may be approximated as

$$
\hat{p}_{p v} \approx\left\{\begin{array}{l}
I_{p v} \hat{v}_{p v}, \quad v_{p v}<\left.v_{p v}\right|_{M P P} \\
-\frac{1}{R_{p v}} \hat{v}_{p v}^{2},\left.\quad v_{p v} \approx v_{p v}\right|_{M P P} . \\
-\frac{V_{p v}}{r_{p v}} \hat{v}_{p v}, \quad v_{p v}>\left.v_{p v}\right|_{M P P} .
\end{array}\right.
$$

The generalized control-to-input-voltage transfer function of the combined PVG-IPC-Load system may be obtained from Equation (8) as

$$
G_{c i}^{p v}(s)=\frac{G_{c i}}{1+Z_{i n} Y_{p v}}=-V_{O} \frac{\omega_{n}^{2}\left(1+s / \omega_{z-e s r}\right)}{s^{2}+2 \zeta_{p v} \omega_{n} s+\omega_{n}^{2}}
$$

While the parameters values in Equation (14) depend on IPC topology, the structure of Equation (14) is IPC topology independent. Therefore, in case of a small-signal duty cycle perturbation given by

$$
\hat{d}(s)=\frac{\Delta d}{s},
$$

corresponding generalized PVG voltage response is given in Laplace and time domains by

$$
\hat{v}_{p v}(s)=\hat{d} \cdot G_{c i}^{p v}=-V_{O} \Delta d\left(\frac{1}{s}-\frac{s+2 \zeta_{p v} \omega_{n}-\frac{\omega_{n}^{2}}{\omega_{z-e s r}}}{s^{2}+s 2 \zeta_{p v} \omega_{n}+\omega_{n}^{2}}\right)
$$

and

$$
\hat{v}_{\mathrm{pv}}(t)=V_{\mathrm{O}} \Delta d\left(1-\frac{\sqrt{1+\frac{\omega_{n}}{\omega_{z-e s t}}\left[\frac{\omega_{n}}{\omega_{z-e s t}}-2 \zeta_{p v}\right]}}{\sqrt{1-\zeta_{p v}^{2}}} \exp \left(-\zeta_{p v} \omega_{n} t\right) \sin \left[\omega_{d} t+\tan ^{-1}\left\{\frac{\sqrt{1-\zeta_{p v}^{2}}}{\zeta \zeta_{p v}-\frac{\omega_{n}}{\omega_{z-e s r}}}\right\}\right]\right)
$$

respectively, with

$$
\omega_{d}=\omega_{n} \sqrt{1-\zeta_{p v}^{2}}
$$

and

$$
0<\zeta_{p v}<1
$$

The practical assumption $\omega_{z \text {-esr }}>>\omega_{n}$ further simplifies Equation (17) as

$$
\hat{v}_{p v}(t) \approx V_{O} \Delta d\left(1-\frac{1}{\sqrt{1-\zeta_{p v}^{2}}} \exp \left(-\zeta_{p v} \omega_{n} t\right) \sin \theta(t)\right),
$$

where

$$
\theta(t)=\omega_{d} t+\tan ^{-1}\left\{\frac{\sqrt{1-\zeta_{p v}^{2}}}{\zeta_{p v}}\right\}
$$


Combining Equation (20) with Equation (13) yields

$$
\hat{p}_{p v}(t) \approx\left\{\begin{array}{l}
-I_{p v} V_{O} \Delta d\left(1 \pm \frac{1}{\sqrt{1-\zeta_{p v}^{2}}} \exp \left(-\zeta_{p v} \omega_{n} t\right) \cdot \sin \theta(t)\right), \quad v_{p v}<<\left.v_{p v}\right|_{M P P} \\
\frac{\left(V_{D C} \Delta d\right)^{2}}{R_{p v}}\left(1-\frac{1}{\sqrt{1-\zeta_{p v}^{2}}} \exp \left(-\zeta_{p v} \omega_{n} t\right) \cdot \sin \theta(t)\right),\left.\quad v_{p v} \approx v_{p v}\right|_{M P P} \\
\frac{V_{p v} V_{O} \Delta d}{r_{p v}}\left(1 \pm \frac{1}{\sqrt{1-\zeta_{p v}^{2}}} \exp \left(-\zeta_{p v} \omega_{n} t\right) \cdot \sin \theta(t)\right), \quad v_{p v}>>\left.v_{p v}\right|_{M P P}
\end{array}\right.
$$

Settling the time of the PVG power transient, imposed by duty cycle perturbation, is then dictated by the corresponding envelope behavior, given by

$$
\operatorname{env}\left(\hat{p}_{p v}(t)\right) \approx\left\{\begin{array}{l}
-I_{p v} V_{O} \Delta d\left(1 \pm \frac{1}{\sqrt{1-\zeta_{p v}^{2}}} \exp \left(-\zeta_{p v} \omega_{n} t\right)\right), \quad v_{p v}<<\left.v_{p v}\right|_{M P P} \\
\frac{\left(V_{D D} \Delta d\right)^{2}}{R_{p v}}\left(1 \pm 2 \frac{1}{\sqrt{1-\zeta_{p v}^{2}}} \exp \left(-\zeta_{p v} \omega_{n} t\right)+\frac{1}{1-\zeta_{p v}^{2}} \exp \left(-2 \zeta_{p v} \omega_{n} t\right)\right),\left.\quad v_{p v} \approx v_{p v}\right|_{M P P} \\
\frac{V_{p v} V_{O} \Delta d}{r_{p v}}\left(1 \pm \frac{1}{\sqrt{1-\zeta_{p v}^{2}}} \exp \left(-\zeta_{p v} \omega_{n} t\right)\right), v_{p v}>>\left.v_{p v}\right|_{M P P}
\end{array}\right.
$$

The corresponding settling times are then obtained as

$$
T_{\Delta} \approx-\left\{\begin{array}{ll}
\frac{1}{\zeta p v \omega_{n}} \ln \left(\Delta \sqrt{1-\zeta_{p v}^{2}}\right), & v_{p v}<<\left.v_{p v}\right|_{M P P} \\
\frac{1}{\zeta p v \omega_{n}} \ln \left(\frac{\Delta}{2} \sqrt{1-\zeta_{p v}^{2}}\right), & \left.v_{p v} \approx v_{p v}\right|_{M P P} \\
\frac{1}{\zeta p v \omega_{n}} \ln \left(\Delta \sqrt{1-\zeta_{p v}^{2}}\right), & v_{p v}>>\left.v_{p v}\right|_{M P P}
\end{array} .\right.
$$

It should be noted that since $\zeta_{p v}$ is dependent on $r_{p v}$ (the two are inversely proportional), settling times must be evaluated considering Equations (5)-(7). Typically, settling time increases monotonically with the decrease of $\zeta_{p v}$ (i.e., with the increase of PVG dynamic resistance). Therefore, $\left.T_{\Delta}\right|_{O C}<$ $\left.T_{\Delta}\right|_{M P P}<\left.T_{\Delta}\right|_{S C}$, and the longest settling time is expected at an SC condition, establishing the operating point for perturbation frequency design in MPPT algorithms with a fixed perturbation frequency. The value of a reciprocal of perturbation frequency should then obey [42]

$$
T_{p} \geq\left. T_{\Delta}\right|_{S C}
$$

\section{Maximum Power Point Tracking (MPPT) with Adaptive Step Size}

MPPT methods with adaptive step are based on directly or indirectly defining an objective function given by $[22,34]$

$$
y[k]=\frac{p_{p v}[k]-p_{p v}[k-1]}{d[k]-d[k-1]}=\frac{\Delta p_{p v}}{\Delta d},
$$

where $k$ is the sampling instant. Since

$$
\begin{aligned}
& >0, \quad v_{p v}<<\left.v_{p v}\right|_{M P P} \\
y[k] & \approx 0,\left.\quad v_{p v} \approx v_{p v}\right|_{M P P} \\
& <0, \quad v_{p v}>>\left.v_{p v}\right|_{M P P}
\end{aligned},
$$

The way of adjusting the duty cycle is as follows:

$$
\left\{\begin{array}{ll}
\text { increased, } & y[k]>0 \\
\text { decreased, } & y[k]<0 \\
\text { maintaind, } & y[k] \approx 0
\end{array} .\right.
$$


Thus, the typical strategy of adapting the duty cycle perturbation at the $(k+1)$ th sampling instant is given by

$$
d[k+1]=d[k]+N \cdot y[k] .
$$

with $N$ referred to as the scaling factor. The size of

$$
\Delta d[k]=N \cdot y[k]
$$

must be kept between two bounds,

$$
\Delta d_{\min }<\Delta d[k]<\Delta d_{\max }
$$

selected as follows. The value of $\Delta d_{\min }$ should be such that the corresponding imposed steady-state PVG power difference, $\Delta p_{p v}$, is higher than the steady-state PVG power difference caused by irradiation change during MPPT algorithm perturbation interval to satisfy [21]:

$$
\Delta d_{\min }=\frac{1}{G_{0}} \sqrt{\frac{\left.V_{p v}\right|_{M P P} \cdot K_{p h} \cdot\left|\dot{G}_{s}\right| \cdot T_{p}}{\left.H \cdot V_{p v}\right|_{M P P}+\left.Y_{p v}\right|_{M P P}}},
$$

where the value of the MPP voltage corresponds to standard test conditions, $K_{p h}=\frac{\partial i_{p v}}{\partial G_{s}}$ denotes the PVG material constant, $G_{0}$ signifies the DC gain of the duty cycle to PVG voltage transfer function in Equation (14), $\dot{G}_{\mathrm{S}}$ represents the solar irradiation change rate, and $H=-\left.\frac{1}{2} \frac{\partial^{2} i_{p v}}{\partial^{2} v_{p v}}\right|_{M P P}$. It is important to highlight that since Equation (32) depends on environmental conditions, the combination of parameters leading to the highest value of $\Delta d_{\text {min }}$ must be utilized, taking into account the worst case of irradiation change rate. It should be emphasized that in addition to irradiation variations, finite resolution of the utilized analog-digital converter (ADC) should also be considered upon selection of $\Delta d_{\min }$ [21]. On the other hand, the selected value of $\Delta d_{\max }$ must keep the PVG voltage within a feasible operation range for all expected operation conditions, satisfying [21]:

$$
\Delta d_{\max }=N \frac{\Delta P_{p v \max }}{\Delta V_{p v \max }}
$$

In fixed-step MPPT algorithms, the high value of $\Delta d$ leads to accelerated convergence, traded off for steady-state accuracy (see Equation (22)) since higher values of $\Delta d$ impose higher power deviations around MPP in steady state. It was shown in [41] that Equation (29) is the discrete-time version of integral-based adjustment

$$
d(t)=d\left(t-T_{p}\right)+\underbrace{\frac{N}{T_{p}} \int_{t-T_{p}}^{t} y(\tau) d \tau}_{\Delta d}
$$

i.e., the size of $\Delta d$ is adjusted according to the objective function value. Unfortunately, while the method of choosing $\Delta d_{\min }$ is relatively simple, the selection of $\Delta d_{\max }$ is often based on a trial-and-error approach, and the value resulting from this process is suitable only for a given system operating under specific operating conditions. Moreover, it is well-known that the Perturb-and-Observe algorithm is confused by sudden irradiation changes, causing significant transients. In some cases this confusion is partially cured by Incremental Conductance which does not solve the issue completely [15] and 
is additionally prone to noise due to its inherent differentiation operation. Lastly, note that the steady-state value of power perturbation is given by (cf. Equation (22))

$$
\Delta \hat{p}_{\mathrm{pv}}(t) \approx\left\{\begin{array}{l}
-I_{\mathrm{pv}} V_{\mathrm{O}} \Delta d, \quad v_{p v}<<\left.v_{p v}\right|_{M P P} \\
\frac{\left(V_{\mathrm{DC}} \Delta d\right)^{2}}{R_{\mathrm{pv}}},\left.\quad v_{p v} \approx v_{p v}\right|_{M P P} \\
\frac{V_{\mathrm{pv}} V_{\mathrm{O}} \Delta d}{r_{\mathrm{pv}}}, \quad v_{p v}>>\left.v_{p v}\right|_{M P P}
\end{array}\right.
$$

i.e., $\Delta \hat{p}_{p v} \sim \Delta d$ when the operating point is away from the MPP and $\Delta \hat{p}_{p v} \sim(\Delta d)^{2}$ when the operating point is in the vicinity of MPP in addition to being operating region dependent. When $\Delta d$ is increased, corresponding overshoots also rise, aggravating unwanted transients. Therefore, it would be desirable to keep the duty cycle at $\Delta d_{\min }$ or slightly above at all times while increasing the algorithm convergence during transients by other means.

\section{Maximum Power Point Tracking (MPPT) with Adaptive Perturbation Frequency}

Consider a time-domain generalization according to Equation (15)

$$
\hat{d}(t)=\Delta d \cdot u\left(t-t_{0}\right)
$$

with $\Delta d<0$ (for demonstration purposes only, without loss of generalization) denoting a step-like duty cycle perturbation at arbitrary $t=t_{0}$. Observing the corresponding time-domain PVG power response $\hat{p}_{p v}\left(t-t_{0}\right)$, it may be concluded from Equation (22) that

$$
\begin{aligned}
<0, \quad v_{p v}<<\left.v_{p v}\right|_{M P P} \\
\hat{p}_{\mathrm{pv}}(t) \quad>0,\left.\quad v_{p v} \approx v_{p v}\right|_{M P P} \\
>0, \quad v_{p v}>>\left.v_{p v}\right|_{M P P}
\end{aligned},
$$

for any $t>t_{0}$. This means that in case the PVG operating point is not in the vicinity of MPP, the sign of power perturbation induced by duty cycle perturbation does not change and may be theoretically detected for any $t>t_{0}$. On the other hand, the steady-state value of the PVG power would not be accurately estimated if sampled before $t=t_{0}+T_{p}$. Therefore, it is proposed to keep the duty cycle perturbation constant at $\Delta d_{\min }$ to obtain maximum accuracy in steady state while adjusting the reciprocal of perturbation frequency (instead of Equation (28)) as

$$
\left\{\begin{array}{l}
\text { decrease } T_{p} \text { below }\left.T_{\Delta}\right|_{S C}, \quad y[k]>0 \\
\text { decrease } T_{p} \text { below }\left.T_{\Delta}\right|_{S C}, \quad y[k]<0 \\
\text { maintain } T_{p}=\left.T_{\Delta}\right|_{S C}, \quad y[k] \approx 0
\end{array} .\right.
$$

A possible strategy of adapting the reciprocal of perturbation frequency at $(k+1)$ th sampling instant is given by

$$
T_{p}[k+1]=T_{p}[k]+M \cdot y[k]
$$

with $M$ referred to as a scaling factor. The size of $T_{p}$ should be kept between two bounds,

$$
T_{p \min }<T_{p}[k]<\left.T_{\Delta}\right|_{S C}
$$

with the lower boundary selected using a similar line of thinking as the selection in $\Delta d_{\min }$ above. In general, the value of $T_{p \min }$ will also be dictated by irradiation-induced variation and system resolution. In-depth investigation is left for future work, as only the concept of variable perturbation frequency is introduced here. The proposed algorithm is expected to be less confused by sudden irradiation changes than the variable step one, since the duty cycle remains unchanged. The increase of 
algorithm convergence time during transients is achieved by means of enlarged perturbation frequency. Moreover, the steady-state value of power perturbation is given by (cf. Equations (22) and (35))

$$
\Delta \hat{p}_{p v}(t) \approx\left\{\begin{array}{l}
-I_{p v} V_{O} \Delta d_{\min }, \quad v_{p v}<<\left.v_{p v}\right|_{M P P} \\
\frac{\left(V_{D C} \Delta d_{\min }\right)^{2}}{R_{p v}},\left.\quad v_{p v} \approx v_{p v}\right|_{M P P} \\
\frac{V_{p v} V_{O} d_{\min }}{r_{p v}}, \quad v_{p v}>>\left.v_{p v}\right|_{M P P}
\end{array},\right.
$$

i.e., the resulting $\Delta \hat{p}_{p v}$ is now operating region dependent only, since $\Delta d$ does not change.

\section{Example}

Consider the system utilized for perturbation frequency design guideline verification in References [42,43], consisting of:

- $\quad$ A 14.6 W PVG with a maximum power point current of $\left.I_{p v}\right|_{M P P}=0.9 \mathrm{~A}$, a maximum power point voltage $\left.V_{p v}\right|_{M P P}=16.2 \mathrm{~V}$, a short-circuit current of $1 \mathrm{~A}$ and an open-circuit voltage of $19.2 \mathrm{~V}$ for values of environmental variables given by $G_{S}=500 \mathrm{~W}, T=45^{\circ} \mathrm{C}$. Under these conditions, shunt and series PVG resistances are estimated as $r_{\mathrm{SH}} \approx 1000 \Omega$ and $r_{\mathrm{S}} \approx 0.91 \Omega$;

- $\quad$ A $100 \mathrm{KHz}$ pulse width modulated boost power stage operating as IPC, terminated by a $26 \mathrm{~V}$ voltage source.

The system is shown in Figure 3 with the rest of the relevant parameters values indicated. PVG voltage $v_{p v}$ and current $i_{p v}$ are the measured variables. Output per-unit PVG characteristics are depicted in Figure 4. Note that $\left.r_{p v}\right|_{M P P}=18 \Omega$ so that $\left.\left.\left.r_{p v}\right|_{O C} \ll r_{p v}\right|_{M P P} \ll r_{p v}\right|_{S C^{\prime}}$, as predicted by Equation (7).

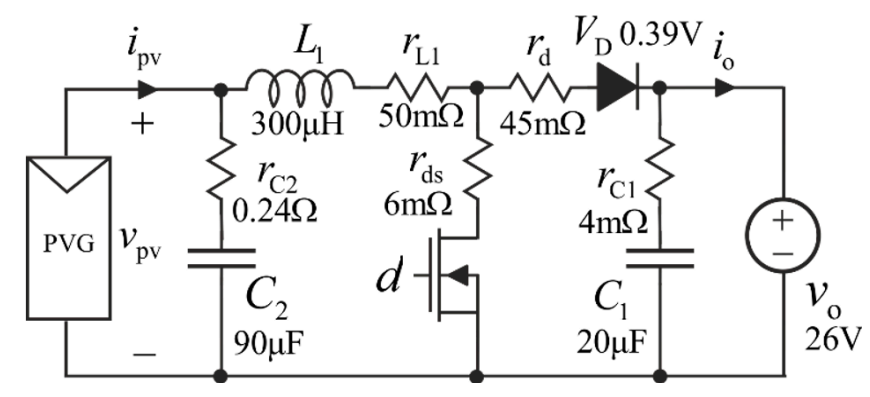

Figure 3. Boost-interfacing power converter (IPC)-based solar energy conversion system.

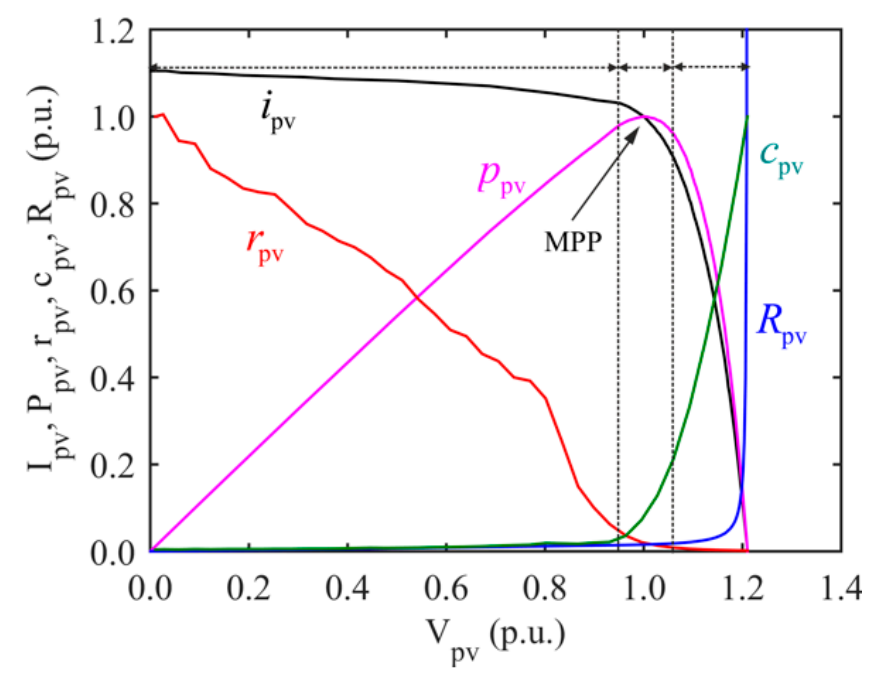

Figure 4. Output per-unit photovoltaic generator (PVG) characteristics. 
The following settling times were revealed in Reference [42] for $\Delta=0.05$ :

$$
T_{\Delta} \approx\left\{\begin{array}{l}
5.6 m s, \quad v_{p v}<<\left.v_{p v}\right|_{M P P} \\
3.3 m s,\left.\quad v_{p v} \approx v_{p v}\right|_{M P P} \\
1.5 m s, \quad v_{p v}>>\left.v_{p v}\right|_{M P P}
\end{array},\right.
$$

Thus, $T_{p}>5.6 \mathrm{~ms}$ should be selected. In order to estimate $\Delta d_{\min }$, the following parameters were used: material constant $K_{p h}=1.9 \mathrm{~mA}$, saturation current $I_{s}=1.097 \cdot 10^{-10} \mathrm{~A}$, and ideality factor $\eta=1.0$, with an irradiation change rate $\dot{G}_{s}$ of $100 \mathrm{~W} / \mathrm{m}^{2} / \mathrm{s}$ and a 12-bit ADC with 3-V full-scale voltage span. The resulting minimum duty cycle perturbation step size was obtained as $\Delta d_{\min }=0.021$. Selecting, for demonstration purposes, $T_{p}=5.7 \mathrm{~ms}$ and $\Delta d=0.025$, Figure 5 demonstrates the results of sweeping the converter duty cycle. It may be concluded that the PVG power curve is sampled with settling times matching Equation (40). Moreover, the claim that the direction of PVG power induced by duty cycle perturbation at $t=t_{0}$ does not change for any $t>t_{0}$ is well evident. For $v_{p v}<\left.v_{p v}\right|_{M P P^{\prime}}$ negative $\Delta d$ yields positive $\Delta p_{p v}$ while for $v_{p v}>\left.v_{p v}\right|_{M P P^{\prime}}$, negative $\Delta d$ yields negative $\Delta p_{p v}$, as predicted by Equation (23).
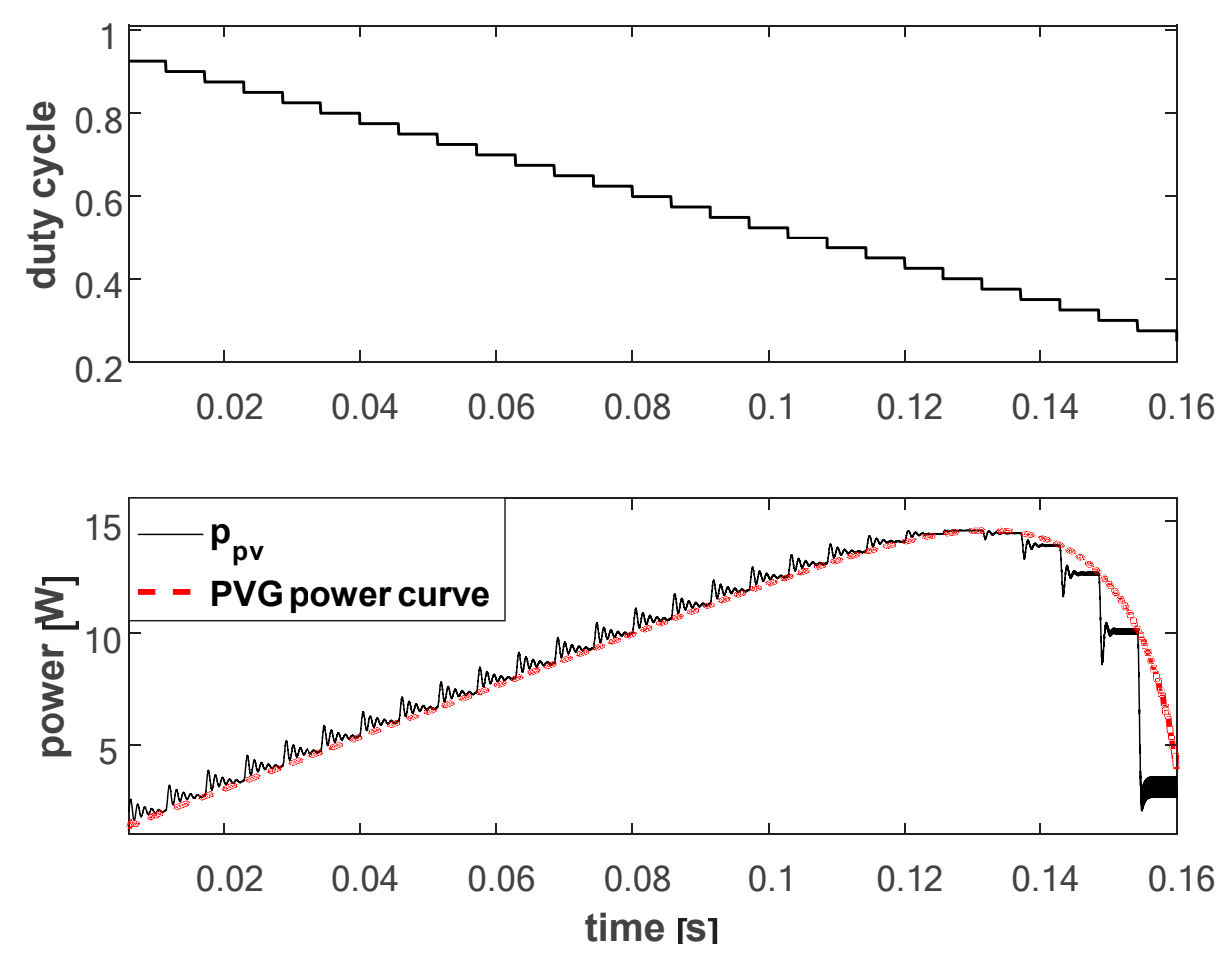

Figure 5. Duty cycle sweeping results.

In order to perform a demonstrative comparison of the system performance under different values of duty cycle and perturbation frequencies, the system was initialized away from MPP under $300 \mathrm{~W} / \mathrm{m}^{2}$ irradiation to observe initial convergence to the MPP. Next, the irradiation was increased to $500 \mathrm{~W} / \mathrm{m}^{2}$ at $t=0.17 \mathrm{~s}$ to examine the corresponding response of the MPPT algorithm.

In the first case, the constant duty cycle constant perturbation frequency MPPT algorithm with $\Delta d$ $=\Delta d_{\min }=0.021$ and $T_{p}=\left.T_{\Delta}\right|_{S C}=5.6 \mathrm{~ms}$ was applied. The results are shown in Figure 6 . The system converges to the MPP corresponding to $300 \mathrm{~W} / \mathrm{m}^{2}$ irradiation after $\sim 120 \mathrm{~ms}$ and then oscillates around the MPP in three discrete steps, as predicted in [21]. Upon irradiation change, the system converges to the new MPP almost instantaneously due to the fact that the MPP voltage is nearly insensitive to irradiation [54]. Therefore, the converter duty cycle should not change significantly upon irradiation variation. This is evident in Figure 6. 

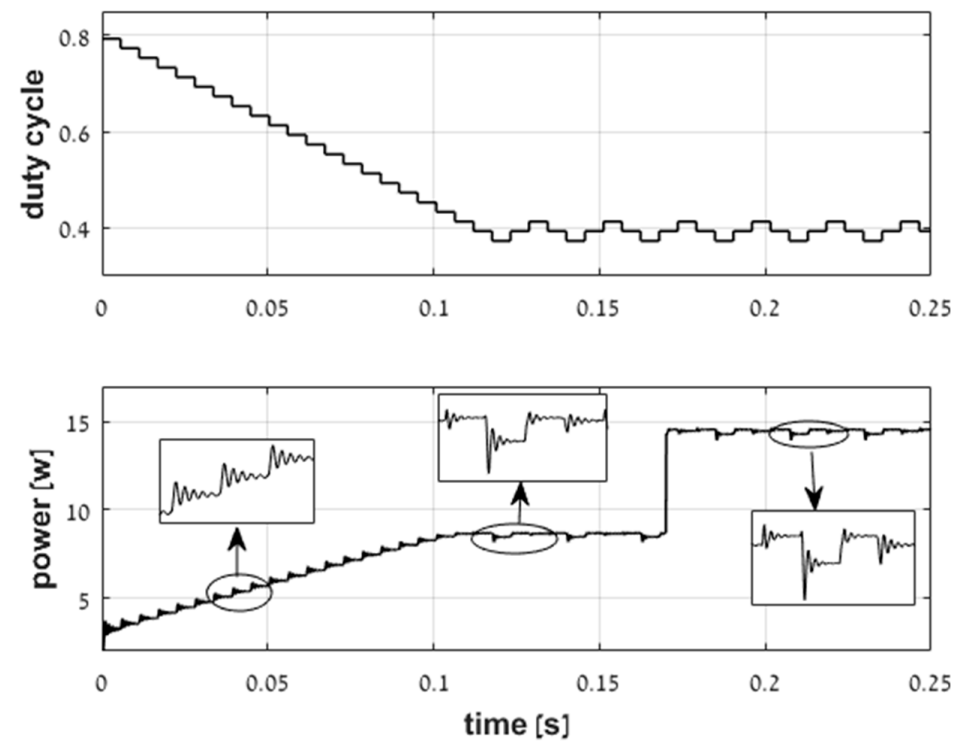

Figure 6. Performance under the constant duty cycle and constant perturbation frequency values of $\Delta d$ $=0.021, T_{p}=5.6 \mathrm{~ms}$.

In the second case, the constant duty cycle constant perturbation frequency MPPT algorithm with $\Delta d=5 \cdot \Delta d_{\min }=0.1$ and $T_{p}=\left.T_{\Delta}\right|_{S C}=5.6 \mathrm{~ms}$ was applied, and the duty cycle was significantly increased. The results are shown in Figure 7. The system converges to the MPP corresponding to $300 \mathrm{~W} / \mathrm{m}^{2}$ irradiation after $\sim 25 \mathrm{~ms}$ - five times faster than in the previous case, as expected-and then oscillates around the MPP in three discrete steps. Nevertheless, the differences between corresponding levels of PVG power and MPP power are much higher than in the previous case, resulting in significant steady state power losses. Moreover, upon irradiation change, the system does not instantaneously converge to the new MPP, since the duty cycle moves away from its optimum region due to confusion and then returns in about $200 \mathrm{~ms}$.
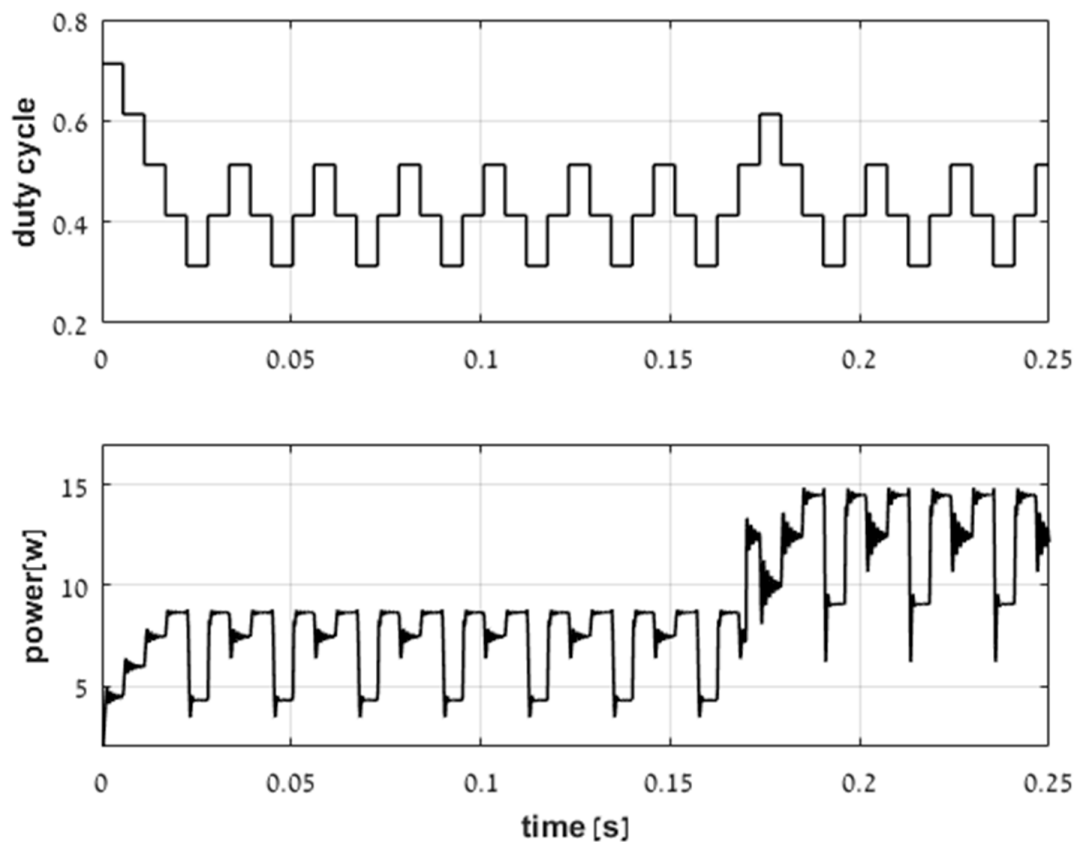

Figure 7. Performance under the constant duty cycle and constant perturbation frequency values of $\Delta d$ $=0.1, T_{p}=5.6 \mathrm{~ms}$. 
In the third case, the constant duty cycle constant perturbation frequency MPPT algorithm with $\Delta d=\Delta d_{\min }=0.021$ and $T_{p}=\left.0.1 \cdot T_{\Delta}\right|_{S C}=0.56 \mathrm{~ms}$ was applied, and the perturbation frequency was significantly increased. The results are shown in Figure 8. The system converges to the MPP corresponding to $300 \mathrm{~W} / \mathrm{m}^{2}$ irradiation after $\sim 12.5 \mathrm{~ms}$-ten times faster than in the first case, as expected-and then oscillates around the MPP in five, rather than three, discrete steps, entering chaotic mode [21]. Consequently, the differences between corresponding levels of PVG power and MPP power are higher than in the first case, resulting in higher steady state power losses. Upon irradiation change, the system instantaneously converges to the new MPP and oscillates around the MPP in three discrete steps, as desired. It may be observed that the power response never settles following a duty cycle perturbation, as predicted.
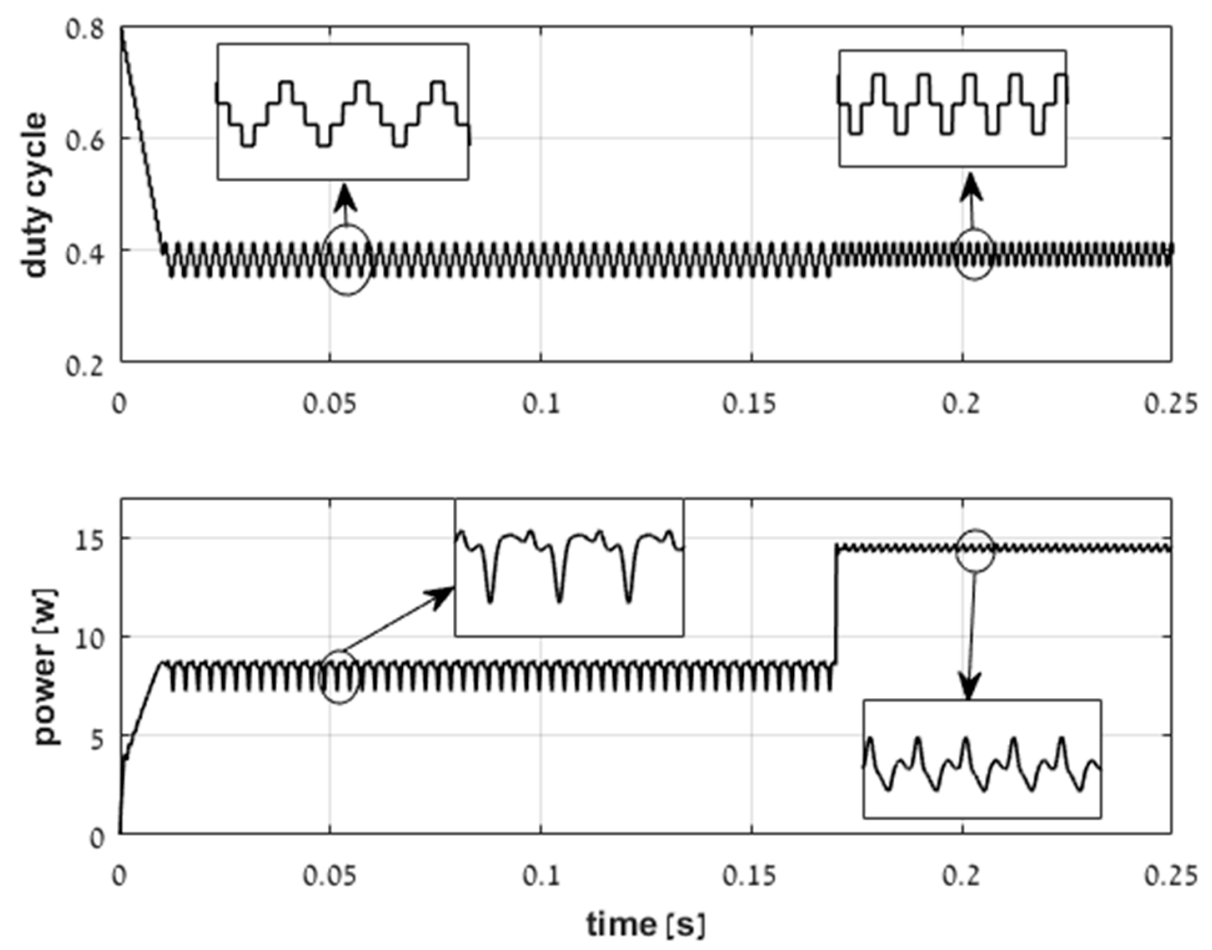

Figure 8. Performance under constant duty cycle and constant perturbation frequency values of $\Delta d=$ $0.021, T_{p}=0.56 \mathrm{~ms}$.

In the fourth case, the variable duty cycle constant perturbation frequency MPPT algorithm with (cf. Equation (31)) $\Delta d_{\min }=0.021<\Delta d<0.1=5 \cdot \Delta d_{\min }$ and $T_{p}=\left.T_{\Delta}\right|_{S C}=5.6 \mathrm{~ms}$ was applied. The duty cycle was adapted according to Equation (29). The results are shown in Figure 9. The system converges to the MPP corresponding to $300 \mathrm{~W} / \mathrm{m}^{2}$ irradiation after $\sim 60 \mathrm{~ms}$ (two times faster than in the first case yet two times slower than in the second) and then oscillates around the MPP in three discrete steps, similar to the first case. However, upon irradiation change, the system undergoes a significant transient and settles in the new MPP only after $\sim 300 \mathrm{~ms}$. This transient is probably the main drawback of perturbative MPPT algorithms with variable step size.

In the last case, the constant duty cycle variable perturbation frequency MPPT algorithm with (cf. Equation (40)) $\Delta d=\Delta d_{\min }=0.021$ and $\left.0.1 \cdot T_{\Delta}\right|_{S C}=0.56 \mathrm{~ms}<T_{p}<\left.T_{\Delta}\right|_{S C}=5.6 \mathrm{~ms}$ was applied. The perturbation frequency was adapted according to Equation (39). The results are shown in Figure 10. The system converges to the MPP corresponding to $300 \mathrm{~W} / \mathrm{m}^{2}$ irradiation after $\sim 40 \mathrm{~ms}$ (three times faster than in the first case yet three times slower than in the third) and then oscillates around the MPP in three discrete steps, similar to the first case. Upon irradiation change, the system converges to the new MPP after a transient lasing a single perturbation period $(5.6 \mathrm{~ms})$ and then oscillates around the MPP in three discrete steps, as desired. 

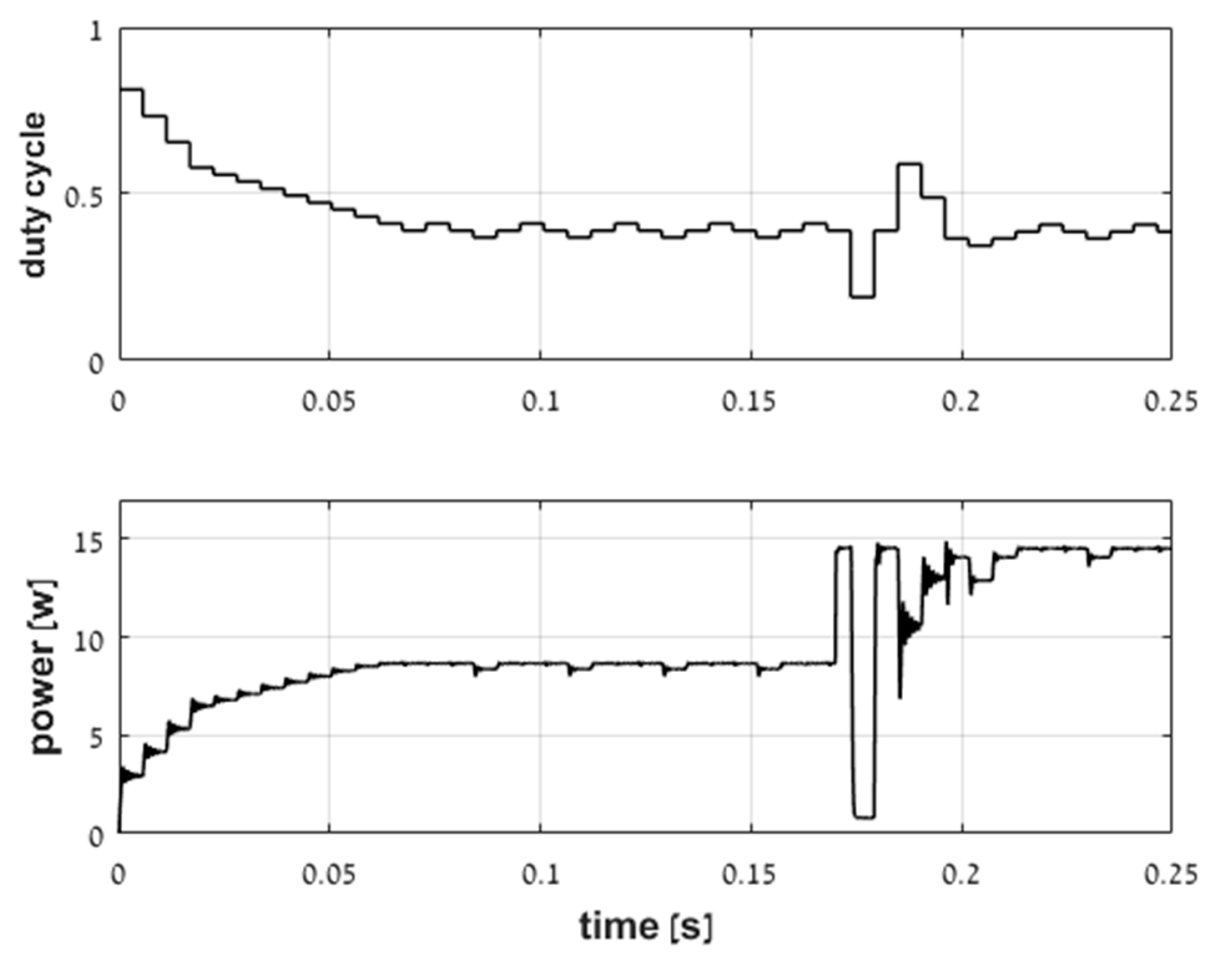

Figure 9. Performance under the variable duty cycle and constant perturbation frequency values of $0.021<\Delta d<0.1, T_{p}=5.6 \mathrm{~ms}$.
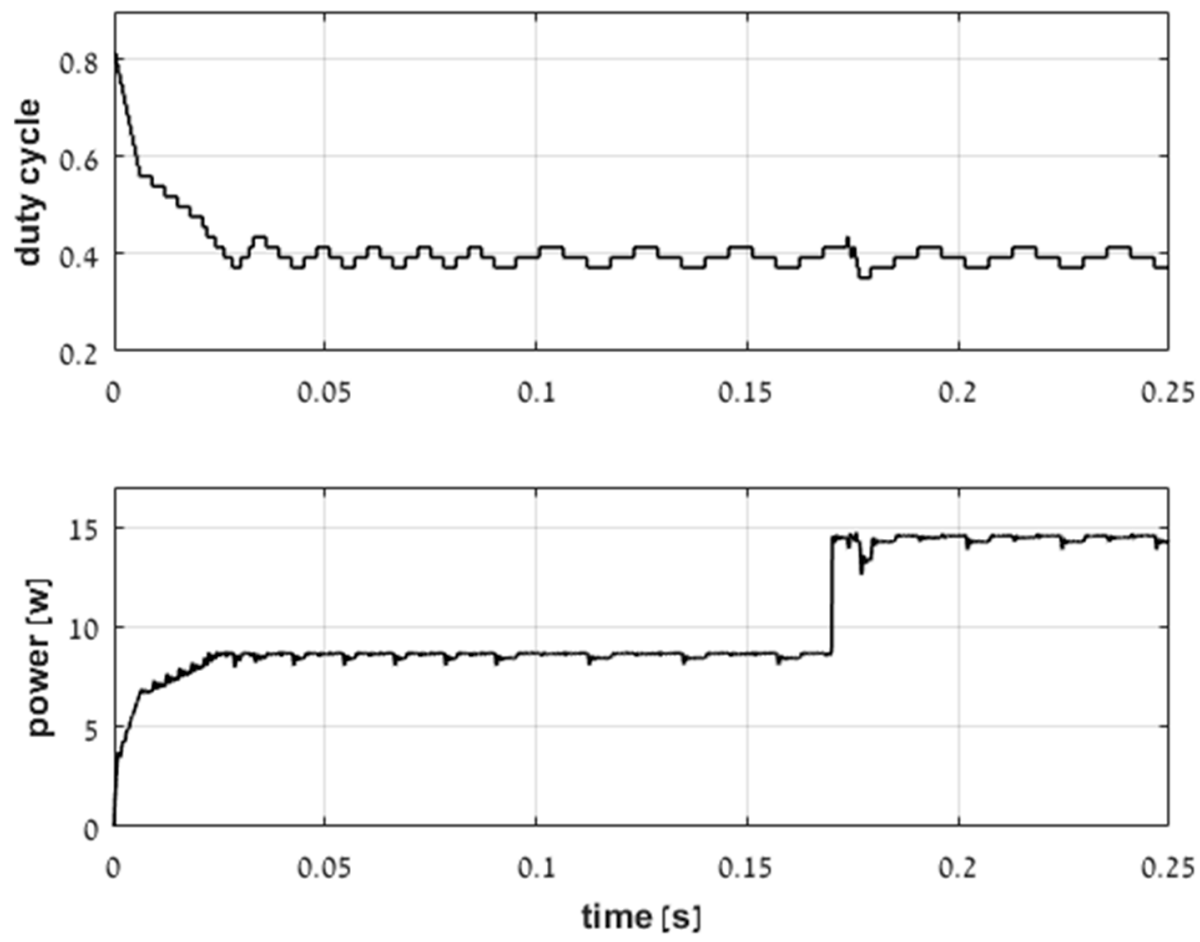

Figure 10. Performance under the constant duty cycle and variable perturbation frequency values of $\Delta d=0.021,0.56 \mathrm{~ms}<T_{p}<5.6 \mathrm{~ms}$.

It may then be concluded that the constant duty cycle variable perturbation frequency MPPT algorithm seems to present a better trade-off between steady-state and transient performance than the fixed step fixed perturbation frequency and variable step fixed perturbation frequency MPPT algorithms. 


\section{Conclusions}

In this paper, the concept of using an MPPT algorithm with an adaptive perturbation frequency instead of the commonly used variable step size was proposed. The analytical background was presented, based on recently revised design guidelines for designing fixed-step direct maximum power point tracking methods. Where possible, it is proposed to keep the step size at a minimum at all times while increasing perturbation frequency during transients and keeping it unchanged (equal to the maximum allowed by design guidelines) in a steady state. Such an approach helps to eliminate algorithm confusion during sudden irradiation changes and prevent excess transients caused by operation with an increased perturbation step. Preliminary results demonstrate the superiority of the proposed method over adaptive perturbation step size operation during transients, gained without compromising steady state performance. Since only the concept of variable perturbation frequency is introduced here, in-depth investigation is left for future work, to yield comprehensive design guidelines by deriving the lower bound of perturbation step time analytically, based on both system parameters and the behavior of environmental variables.

Author Contributions: E.A. conducted the research referred to in the paper during his M.Sc. studies. A.K. wrote the paper and supervised the research related to the paper with T.S.

Funding: This research received no external funding.

Conflicts of Interest: The authors declare no conflict of interest.

\section{References}

1. Gadelovits, S.; Kuperman, A.; Sitbon, M.; Aharon, I.; Singer, S. Interfacing renewable energy sources for maximum power transfer-Part I: Statics. Renew. Sustain. Energy Rev. 2014, 31, 501-508. [CrossRef]

2. Kolesnik, S.; Sitbon, M.; Gadelovits, S.; Suntio, T.; Kuperman, A. Interfacing renewable energy sources for maximum power transfer-Part II: Dynamics. Renew. Sustain. Energy Rev. 2015, 51, 1771-1783. [CrossRef]

3. de Brito, M.A.G.; Galotto, L., Jr.; Sampaio, L.P.; Melo, G.D.E.; Canesin, C.A. Evaluation of the main MPPT techniques for photovoltaic applications. IEEE Trans. Ind. Electron. 2013, 60, 1156-1167. [CrossRef]

4. Esram, T.; Chapman, P.L. Comparison of photovoltaic array maximum power point tracking techniques. IEEE Trans. Energy Convers. 2007, 22, 439-449. [CrossRef]

5. Faranda, R.; Leva, S. Energy comparison of MPPT techniques for PV systems. WSEAS Trans. Power Syst. 2008, 3, 446-455.

6. Lyden, S.; Haque, M.E. Maximum power point tracking techniques for photovoltaic systems: A comprehensive review and comparative analysis. Renew. Sustain. Energy Rev. 2015, 52, 1504-1518. [CrossRef]

7. Xiao, W.; Zeineldin, H.H.; Zhang, P. Statistic and parallel testing procedure for evaluating maximum power point tracking algorithms of photovoltaic power systems. IEEE J. Photovolt. 2013, 3, 1062-1069. [CrossRef]

8. Subudhi, B.; Pradhan, R. A comparative study on maximum power point tracking techniques for photovoltaic power systems. IEEE Trans. Sustain. Energy 2013, 4, 89-98. [CrossRef]

9. Latham, A.M.; Pilawa-Podgurski, R.; Odame, K.M.; Sullivan, C.R. Analysis and optimization of maximum power point tracking algorithms in the presence of noise. IEEE Trans. Power Electron. 2013, 28, 3479-3494. [CrossRef]

10. Andrean, V.; Chang, P.C.; Lian, K.L. A review and new problems discovery of four simple decentralized maximum power point tracking algorithms-Perturb and observe, incremental conductance, golden section search, and Newton's quadratic interpolation. Energies 2018, 11, 2966. [CrossRef]

11. Danandeh, M.A.; Mousavi, S.M. Comparative and comprehensive review of maximum power point tracking methods for PV cells. Renew. Sustain. Energy Rev. 2018, 82, 2743-2767. [CrossRef]

12. Koutroulis, E.; Kalaitzakis, K.; Voulgaris, N.C. Development of a microcontroller-based, photovoltaic maximum power point tracking control system. IEEE Trans. Power Electron. 2001, 16, 46-54. [CrossRef]

13. Femia, N.; Petrone, G.; Spagnuolo, G.; Vitelli, M. Optimization of perturb and observe maximum power point tracking method. IEEE Trans. Power Electron. 2005, 20, 963-973. [CrossRef]

14. Hussein, K.H.; Muta, I.; Hoshino, T.; Osakada, M. Maximum photovoltaic power tracking: An algorithm for rapidly changing atmospheric conditions. IEE Proc. Gener. Transm. Distrib. 1995, 142, 59-64. [CrossRef] 
15. Elgendy, M.A.; Zahawi, B.; Atkinson, D.J. Assessment of the incremental conductance maximum power point tracking algorithm. IEEE Trans. Sustain. Energy 2013, 4, 108-117. [CrossRef]

16. Leyva, R.; Alonso, C.; Queinnec, I.; Cid-Pastor, A.; Lagrange, D.; Martinez-Salamero, L. MPPT of photovoltaic systems using extremum seeking control. IEEE Trans. Aerosp. Electron. Syst. 2006, 42, 249-258. [CrossRef]

17. Ghaffari, A.; Krstic, M.; Seshagiri, S. Power optimization and control in wind energy conversion systems using extremum seeking. IEEE Trans. Contr. Syst. Technol. 2014, 22, 1684-1695. [CrossRef]

18. Brunton, S.L.; Rowley, C.W.; Kulkarni, S.R.; Clarkson, C. Maximum power point tracking for photovoltaic optimization using ripple-based extremum seeking control. IEEE Trans. Power Electron. 2010, 25, 2531-2540. [CrossRef]

19. Esram, T.; Kimball, J.W.; Krein, P.T.; Chapman, P.L.; Midya, P. Dynamic maximum power point tracking of photovoltaic arrays using ripple correlation control. IEEE Trans. Power Electron. 2006, 21, 1282-1291. [CrossRef]

20. Bazzi, A.M.; Krein, P.T. Ripple correlation control: An extremum seeking control perspective for real time optimization. IEEE Trans. Power Electron. 2014, 29, 988-995. [CrossRef]

21. Femia, N.; Petrone, G.; Spagnuolo, G.; Vitelli, M. Power Electronics and Control Techniques for Maximum Energy Harvesting in Photovoltaic Systems; CRC Press: Boca Raton, FL, USA, 2013.

22. Liu, F.; Duan, S.; Liu, F.; Liu, B.; Kang, Y. A variable step size INC MPPT method for PV systems. IEEE Trans. Ind. Electron. 2008, 55, 2622-2628.

23. Libo, W.; Zhengming, Z.; Jianzheng, L. A single stage three phase grid connected photovoltaic system with modified MPPT method and reactive power compensation. IEEE Trans. Energy Convers. 2007, 22, 881-886. [CrossRef]

24. Kim, R.-Y.; Lai, J.-S.; York, B.; Koran, A. Analysis and design of maximum power point tracking scheme for thermoelectric battery energy storage system. IEEE Trans. Ind. Electron. 2009, 56, 3709-3716.

25. Xiao, W.; Dunford, W.G. A modified adaptive hill climbing MPPT method for photovoltaic power systems. In Proceedings of the 35th IEEE Annual Power Electronics Specialists Conference (PESC 04), Aachen, Germany, 20-25 June 2004; pp. 1957-1963.

26. Pandey, A.; Dasgupta, N.; Mukerjee, A.K. Design issues in implementing MPPT for improved tracking and dynamic performance. In Proceedings of the 32nd IEEE Annual Industrial Electronics Conference (IECON 2006), Paris, France, 7-10 November 2006; pp. 4387-4391.

27. Mei, Q.; Shan, M.; Liu, L.; Guerrero, J.M. A novel improved variable step-size incremental-resistance MPPT method for PV systems. IEEE Trans. Ind. Electron. 2011, 58, 2427-2434. [CrossRef]

28. Lee, K.-J.; Kim, R.-Y. An adaptive maximum power point tracking scheme based on a variable scaling factor for photovoltaic systems. IEEE Trans. Energy Convers. 2012, 27, 1002-1008. [CrossRef]

29. Khanna, R.; Zhang, Q.; Stanchina, W.E.; Reed, G.F.; Mao, Z.-H. Maximum power point tracking using model reference adaptive control. IEEE Trans. Power Electron. 2014, 29, 1490-1499. [CrossRef]

30. Manganiello, P.; Ricco, M.; Petrone, G.; Monmasson, E.; Spagnuolo, G. Optimization of perturbative PV MPPT methods through online system identification. IEEE Trans. Ind. Electron. 2014, 61, 6812-6821. [CrossRef]

31. Sitbon, M.; Schacham, S.; Kuperman, A. Disturbance observer based voltage regulation of current mode boost converter interfaced photovoltaic generator. IEEE Trans. Ind. Electron. 2015, 62, 5776-5785. [CrossRef]

32. Manganiello, P.; Ricco, M.; Petrone, G.; Monmasson, E.; Spagnuolo, G. Dual Kalman filter based identification and real-time optimization of PV systems. IEEE Trans. Ind. Electron. 2015, 62, 7266-7275. [CrossRef]

33. Li, C.; Chen, Y.; Zhou, D.; Liu, J.; Zeng, J. A high-performance adaptive incremental conductance MPPT algorithm for photovoltaic systems. Energies 2016, 9, 288. [CrossRef]

34. Kou, Y.; Xia, Y.; Ye, Y. Fast variable step maximum power point tracking method for photovoltaic systems. J. Renew. Sustain. Energy 2015, 7, 043126. [CrossRef]

35. Amir, A.; Amir, A.; Selvaraj, J.; Rahim, N.A.; Abusorrah, A.M. Conventional and modified MPPT techniques with direct control and dual scaled adaptive step size. Sol. Energy 2017, 157, 1017-1031. [CrossRef]

36. Tan, C.Y.; Rahim, N.A.; Selvaraj, J. Employing dual scaling mode for adaptive hill climbing method $\mathrm{n}$ buck converter. IET Renew. Power Gen. 2015, 9, 1010-1018. [CrossRef]

37. Ahmed, E.M.; Shoyama, M. Variable step size maximum power point tracker using a single variable for stand alone battery storage PV systems. J. Power Electron. 2011, 11, 218-227. [CrossRef]

38. Ahmed, E.M.; Shoyama, M. Scaling factor design based variable step size incremental resistance maximum power point tracking for PV systems. J. Power Electron. 2012, 12, 164-171. [CrossRef] 
39. Kjaer, S.B. Evaluation of the 'Hill Climbing' and the 'Incremental Conductance' maximum power point trackers for photovoltaic power systems. IEEE Trans. Energy Convers. 2012, 27, 922-929. [CrossRef]

40. Sera, D.; Mathe, L.; Kerekes, T.; Spataru, S.V.; Teodorescu, R. On the perturb-and-observe and incremental conductance MPPT methods for PV systems. IEEE J. Photovolt. 2013, 3, 1070-1078. [CrossRef]

41. Kolesnik, S.; Kuperman, A. On the equivalence of major variable step size MPPT algorithms. IEEE J. Photovolt. 2016, 6, 590-594. [CrossRef]

42. Kivimäki, J.; Kolesnik, S.; Sitbon, M.; Suntio, T.; Kuperman, A. Revisited perturbation frequency design guideline for direct fixed-step maximum power point tracking algorithms. IEEE Trans. Ind. Electron. 2017, 64, 4601-4609. [CrossRef]

43. Kivimäki, J.; Kolesnik, S.; Sitbon, M.; Suntio, T.; Kuperman, A. Design guidelines for multi-loop perturbative maximum power point tracking algorithms. IEEE Trans. Power Electron. 2018, 33, 1284-1293. [CrossRef]

44. Elgendy, M.A.; Atkinson, D.J.; Zahavi, B. Experimental investigation of the incremental conductance maximum power point tracking algorithm at high perturbation rates. IET Renew. Power Gener. 2016, 10, 133-139. [CrossRef]

45. Elgendy, M.A.; Zahavi, B.; Atkinson, D.J. Operating characteristics of the $\mathrm{P} \& \mathrm{O}$ algorithm at high perturbation frequencies for standalone PV systems. IEEE Trans. Energy Convers. 2015, 30, 189-198.

46. Jiang, Y.; Qahoug, J.A.A.; Haskew, T.A. Adaptive step size with adaptive perturbation frequency digital MPPT controller for a single-sensor photovoltaic solar system. IEEE Trans. Power Electron. 2013, 28, 3195-3205. [CrossRef]

47. Nousiainen, L.; Puukko, J.; Mäki, A. Photovoltaic generator as an input source for power electronic converters. IEEE Trans. Power Electron. 2013, 28, 3028-3037. [CrossRef]

48. Suntio, T.; Messo, T.; Aapro, A.; Kivimäki, J.; Kuperman, A. Review of PV generator as an input source for power electronic converters. Energies 2017, 10, 1076. [CrossRef]

49. Lineykin, S.; Averbukh, M.; Kuperman, A. An improved approach to extracting the single-diode equivalent circuit parameters of a photovoltaic cell/panel. Renew. Sustain. Energy Rev. 2014, 30, 282-289. [CrossRef]

50. Averbukh, M.; Lineykin, S.; Kuperman, A. Obtaining PV panel operational curves for arbitrary cell temperatures and solar irradiation densities from standard conditions data. Prog. Photovolt. Res. Appl. 2013, 21, 1016-1024.

51. Lineykin, S.; Averbukh, M.; Kuperman, A. Issues in modeling amorphous silicon photovoltaic modules by single-diode equivalent circuit. IEEE Trans. Ind. Electron. 2014, 61, 6785-6793. [CrossRef]

52. Suntio, T.; Viinamaki, J.; Jokipii, J.; Messo, T.; Kuperman, A. Dynamic characterization of power electronics interfaces. IEEE J. Emerg. Sel. Top. Power Electron. 2014, 2, 949-961. [CrossRef]

53. Sitbon, M.; Leppaaho, J.; Suntio, T.; Kuperman, A. Dynamics of photovoltaic-generator-interfacing voltage-controlled buck power stage. IEEE J. Photovolt. 2015, 5, 633-670. [CrossRef]

54. Kuperman, A.; Averbukh, M.; Lineykin, S. Maximum power point matching versus maximum power point tracking for solar generators. Renew. Sustain. Energy Rev. 2013, 19, 11-17. [CrossRef] 